\title{
ROMARIA DE SÃO GONÇALO: IMAGENS DE FÉ E FESTA NO INTERIOR DO PARANÁ
}

\section{PILGRIMAGE OF SÃO GONCCALO: IMAGES OF FAITH AND CELEBRATION IN THE INTERIOR OF PARANÁ}

\section{Taisa Lewitzki}

taisa.cabocla@gmail.com

Antropóloga, doutoranda em Antropologia Social na Universidade Federal do Rio Grande do Norte (PPGAS/UFRN).

ORCID: https://orcid.org/0000-0002-5098-6598

\section{Douglas Fróis}

douglasfrois77@gmail.com

Fotógrafo do Museu de Arqueologia e Etnologia da Universidade Federal do Paraná (MAE/UFPR). ORCID: https://orcid.org/0000-0002$7330-8140$

\section{(2) $\odot \Theta \odot$}

Esta obra está licenciada sob uma licença Creative Commons Attribution-NonCommercial-ShareAlike 4.0 International License.

O presente ensaio visual é resultado da parceria entre uma antropóloga e um fotógrafo, ambos vinculados à Universidade Federal do Paraná (UFPR). O registro fotográfico foi elaborado no ano de 2018 durante o trabalho de campo etnográfico com comunidades tradicionais de faxinais situadas na região centro sul do Paraná, no âmbito da pesquisa de mestrado desenvolvida pela autora no Programa de Pós-Graduação em Antropologia da UFPR, intitulada "A vida das benzedeiras: caminhos e movimentos”. O objetivo é abordar a Romaria de São Gonçalo como marcador identitário dos povos do campo do interior do Paraná, através de imagens de fé e festa que fazem parte do modo de ser e viver nas comunidades tradicionais de faxinais.

A partir da perspectiva da antropologia visual compartilhada como método de trabalho entre os autores, as fotos foram produzidas, organizadas e selecionadas por meio de diálogos viabilizados pelo trabalho de campo conjunto, realizado durante a Romaria de São Gonçalo e Festa de São João Batista, organizada pela Família Moraes na comunidade rural de Góes Artigas - Km 101, município de Inácio Martins (PR), no dia 24 de junho de 2018. A Família Moraes é formada por pequenos agricultores de raízes negras, que se organizam como faxinalenses (LEWITZKI, 2015), ao compartilharem terras de uso comum para criação de animais à solta, praticarem agricultura familiar e extrativismo, e manifestarem formas próprias de celebrar o sagrado, como a devoção aos Olhos d’Água do Monge João Maria e a celebração da Recomenda de Almas. 
A romaria ou dança de São Gonçalo é uma manifestação cultural e religiosa que faz parte da identidade dos povos do campo da região centro-sul do Paraná, ao que corresponde o universo rural das comunidades tradicionais de faxinais (GAPINSKI; CAMPIGOTO, 2010), benzedeiras (LEWITZKI, 2019) e quilombolas (ALMEIDA, 2009). Ademais, é observada como referência cultural das comunidades quilombolas do Vale do Ribeira, no limite dos estados do Paraná e São Paulo (ISA, 2013), assim como em quilombos na Chapada dos Veadeiros em Goiás (SANTOS, 2013), sem adentrar à presença da dança na zona rural do Nordeste brasileiro (SILVA, 2018).

A dança, difundida pelo catolicismo popular, celebra o santo português reconhecido como tocador e casamenteiro. As formas de celebrar a romaria no contexto paranaense apresentam variações que demonstram a diversidade das formas de celebrar o sagrado na região da floresta de araucárias. No entanto, mantêm sua principal característica, a dança, que consiste em fileiras organizadas por gênero (homens e mulheres), coordenadas por tocadores de violão (tocadores ou romeiros), seguidas de cantadeiras e demais devotas/os, que dançam e cantam frente ao altar, composto primeiramente pela imagem de São Gonçalo.

A festa, realizada anualmente pela Família Moraes na semana em que se comemora o dia de São João Batista (24 de junho), é única, porque articula ritos que celebram a fé e a devoção das/os devotas/os de São Gonçalo e São João Batista em um mesmo dia. Segundo as narrativas das/os festeiras/os, não há registros exatos sobre o início da festa, mas sabe-se que os avós e bisavós das/os festeiras/os atuais que se encontram na faixa etária de 60 anos já realizavam o ritual em decorrência ao pagamento de promessa aos santos festeiros, unindo festejos em homenagem a São Gonçalo e São João Batista.

A celebração articula elementos que refletem o modo de vida das comunidades tradicionais de faxinais, permeada por saberes e fazeres tradicionais, observados nas (1) expressões da religiosidade popular como danças, cantorias e procissões; (2) práticas socioprodutivas, considerando que o ritual demarca a passagem de ciclos naturais e períodos de cultivo e colheita; (3) formas de sociabilidade local, através da reunião de parentes, vizinhos e compadres que compartilham jogos de leilão e caeiras, consumo de alimentos e bebidas que fazem parte da cultura nutricional como a quirera com carne de porco de lata, pinhão, chimarrão e quentão; (4) saberes e fazeres tradicionais que envolvem a organização da festa e o uso da sociobiodiversidade local, com ênfase no preparo do mastro, das fogueiras e da comida; e, (5) processos de transmissão de conhecimentos tradicionais, através do parentesco, com destaque para ofícios de romeiro ou tocador, cantadeira e rezadeira, capelão, preparadeira do altar, hospedeira e festeira/o.

As imagens que compõem o ensaio, organizadas em ordem cronológica, são um convite visual para conhecer e participar da festa, seguindo 
seus ritos e sociabilidades. A começar pelo altar, que ocupa a centralidade ritual da casa (Figura 1) e o jantar que acolhe as/os festeiras/os que chegam (Figura 2). Seguido da dança de São Gonçalo (Figuras 3, 4 e 5), as sociabilidades entre danças (Figuras 6, 7 e 8) e a procissão de São João Batista no andor, que tem como ápice a lavagem do santo no rio e a erguida de mastro com imensa explosão de fogos (Figuras 9, 10, 11, 12 e 13). O ensaio se encerra com a novena de oferecimento da festa (Figuras 14 e 15), que é o rito final de agradecimento.

A importância do ensaio fotográfico consiste no registro da festa, desde uma perspectiva antropológica e etnográfica das narrativas, práticas, conhecimentos, saberes e fazeres tradicionais acionados e manifestados durante o ritual, que revelam o modo de vida faxinalense e suas práticas culturais que configuram uma forma específica de ser e viver no interior paranaense. Além disso, é uma pesquisa realizada de forma compartilhada entre antropologia, fotografia e etnografia, com base no diálogo e produção conjunta entre os autores, a partir da consulta à Família Moraes.

\section{REFERÊNCIAS}

ALMEIDA, Valderez Pontarolo. As práticas tradicionais religiosas da comunidade quilombola Invernada Paiol de Telha Fundão: estudo de caso sobre a prática da recomenda das almas. In: SEED, Paraná (org). O professor PDE e os desafios da escola pública paranaense. Curitiba: SEED/PR, 2009.

GAPINSKI, Ivan; CAMPIGOTO, José A. A dança de São Gonçalo nos faxinais de Rio Azul-PR. Revista Tempo, Espaço e Linguagem (TEL), v. 1, n. 3, p. 43-69. set./dez. 2010.

INSTITUTO SOCIOAMBIENTAL. Inventário Cultural de Quilombos do Vale do Ribeira. Disponível em: <https://acervo.socioambiental. org/sites/default/files/publications/pdf-publicacao-final_inventario. pdf $>$. Acesso em: 05 jul. 2020.

LEWITZKI, Taisa. Concepções sobre conservação ambiental: um estudo etnográfico. Trabalho de Conclusão de Curso (Bacharelado em Antropologia) - Departamento de Antropologia, Universidade Federal da Integração Latino-Americana, Foz do Iguaçu, 2015.

LEWITZKI, Taisa. A vida das benzedeiras: caminhos e movimentos. Dissertação (Mestrado em Antropologia) - Departamento de Antropologia, Universidade Federal do Paraná, Curitiba, 2019.

SANTOS, Nilça Fernandes dos. Romaria de São Gonçalo: festa e tradição na comunidade Vão do Moleque, Cavalcante-GO. Trabalho de Conclusão de Curso (Licenciatura em Educação do Campo) - Universidade de Brasília, Planaltina, 2013.

SILVA, Márcio Douglas de Carvalho. Devoções populares no Brasil: o ritual de pagamento de promessa a São Gonçalo de Amarante. Fórum Sociológico, n. 33, 2018. Disponível em: <http://journals.openedition.org/sociologico/2588>. Acesso em: 19 dez. 2020. 
Figura 1 - Altar de São Gonçalo e São João Batista

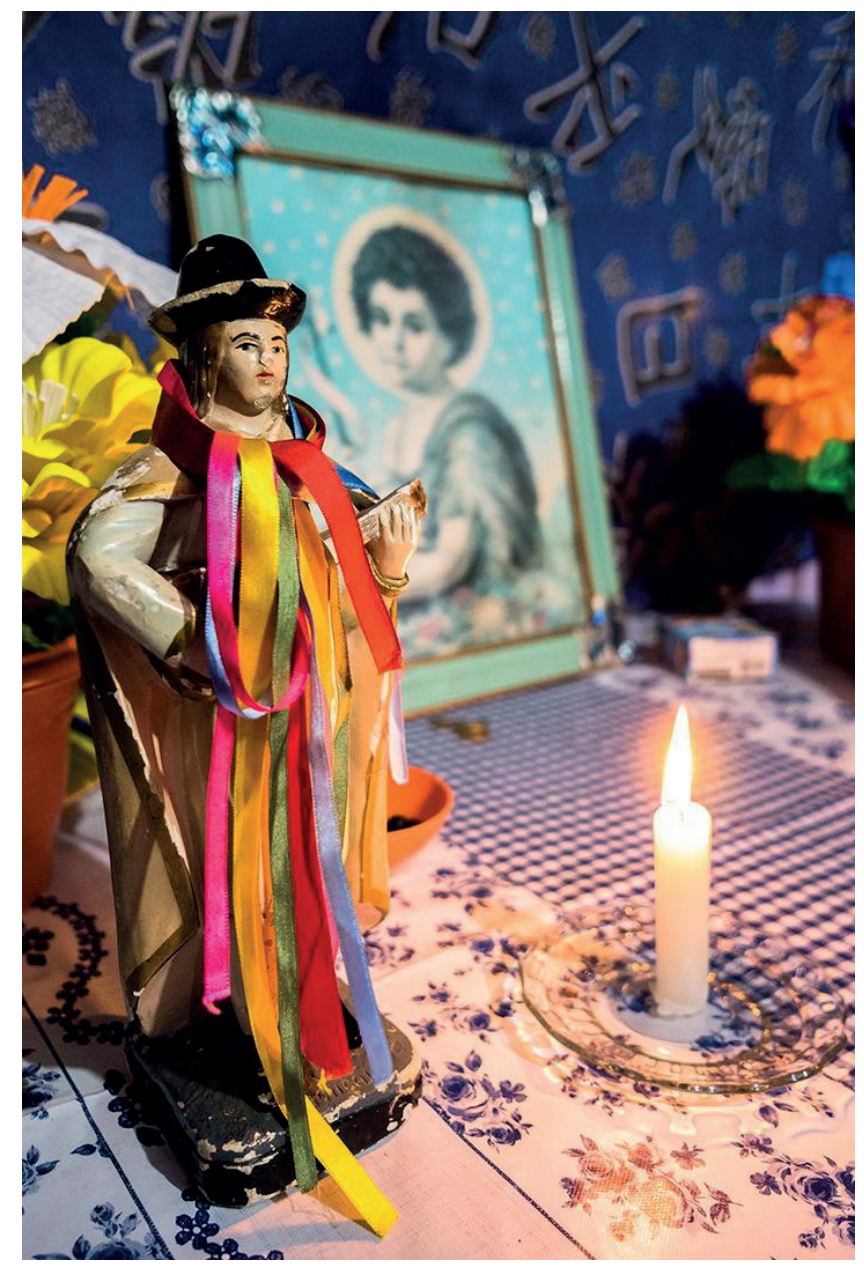

Figura 2 - Quirera com carne de porco de lata

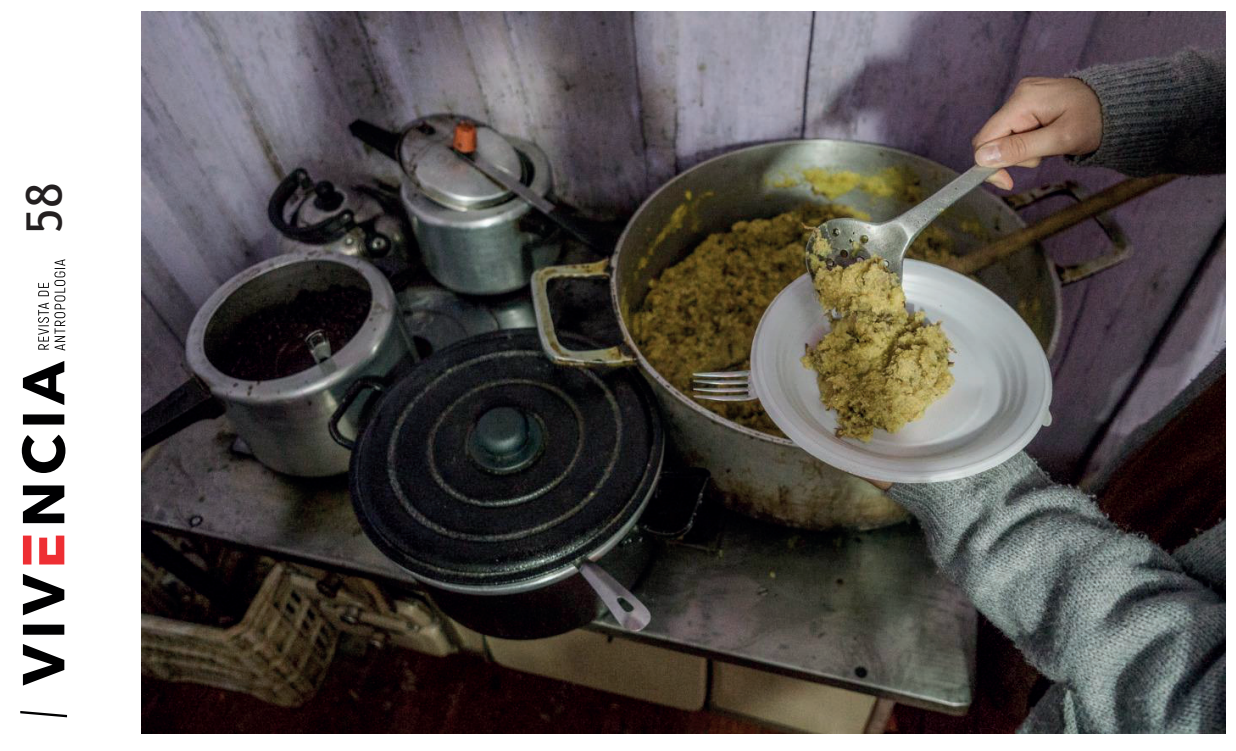


Figura 3 - Dança de São Gonçalo

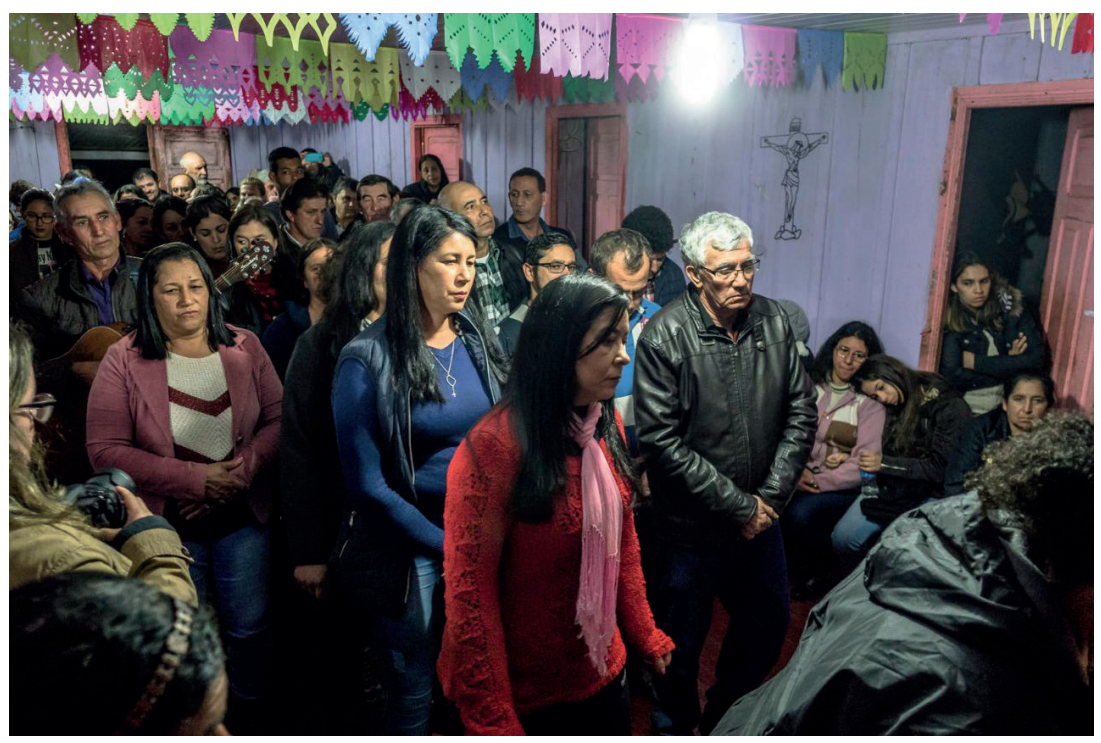

Figura 4 - Dança de São Gonçalo

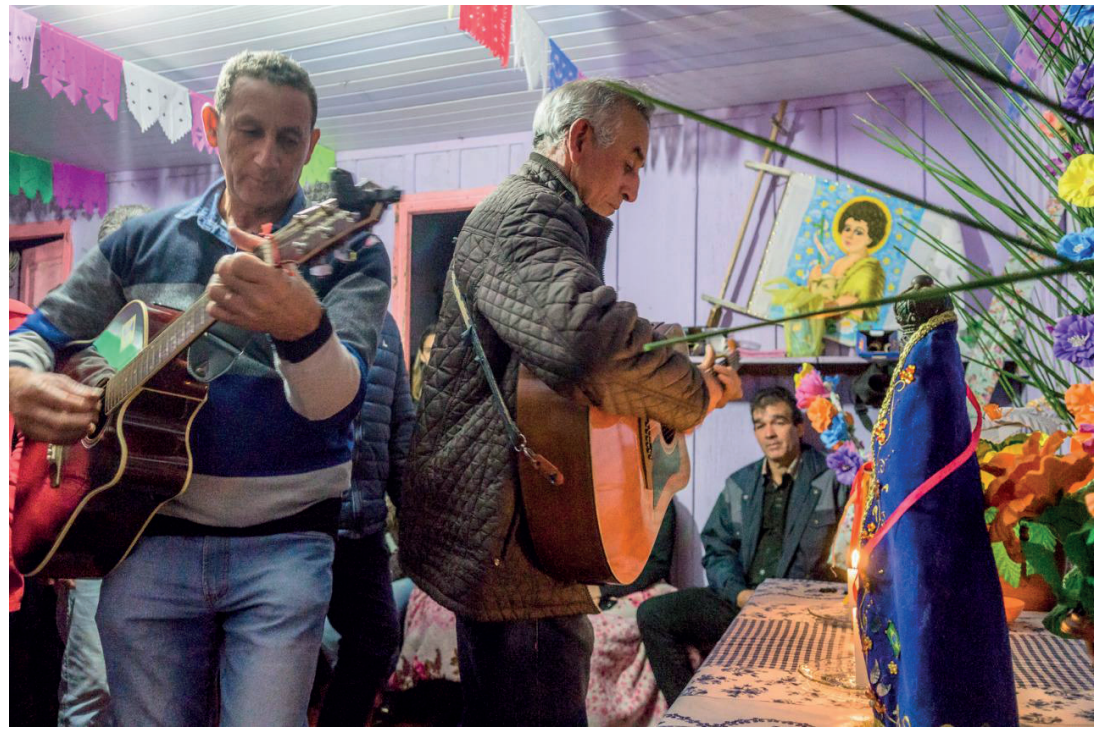

Figura 5 - Dança de São Gonçalo

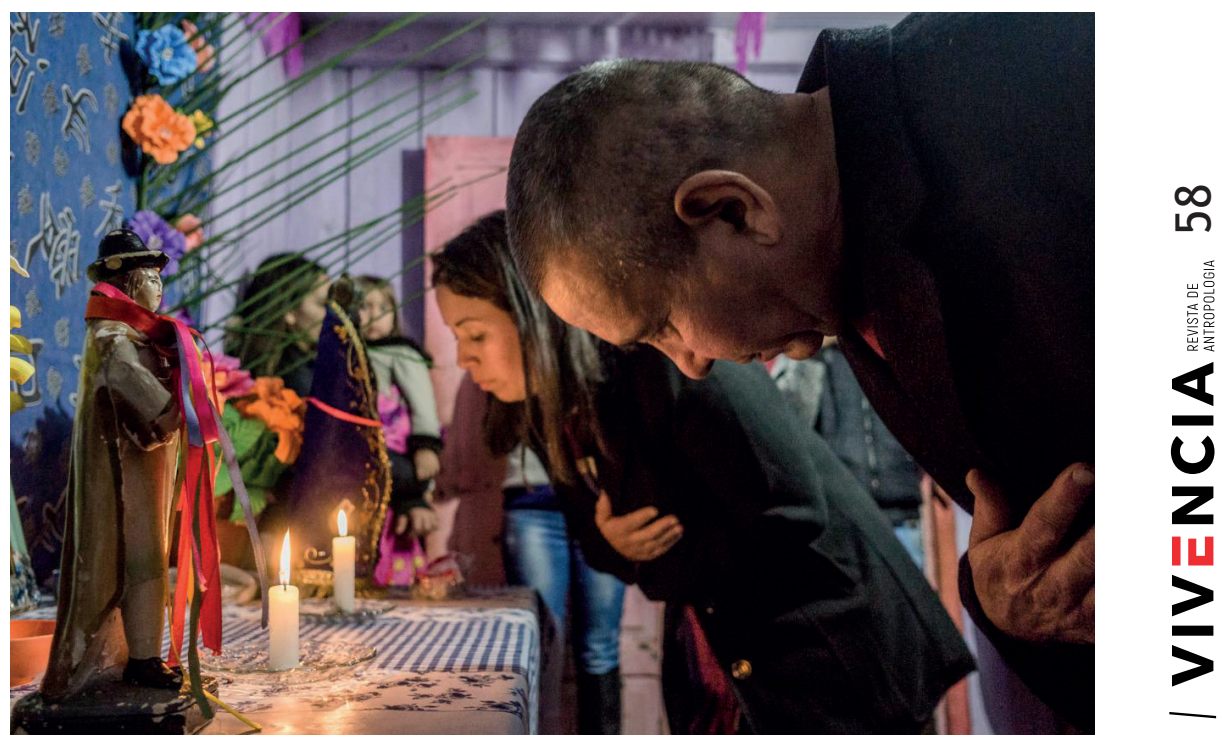


Figura 6 - Entre danças - pinhão

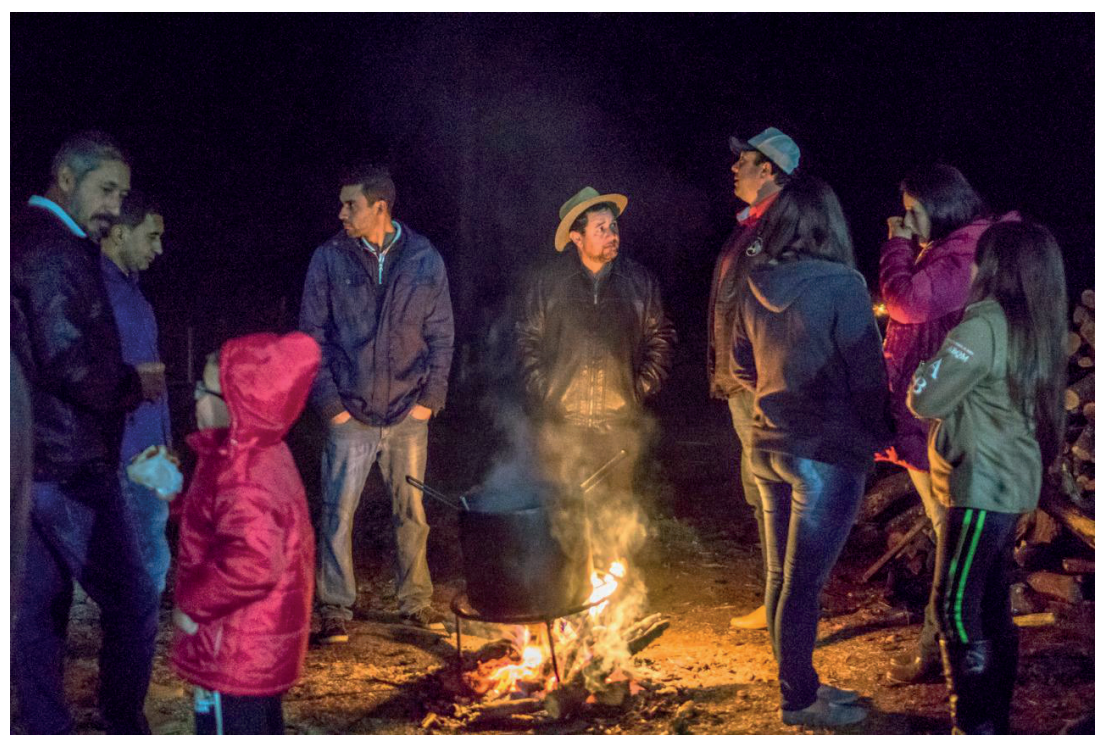

Figura 7 - Entre danças - caeira (fogueira)

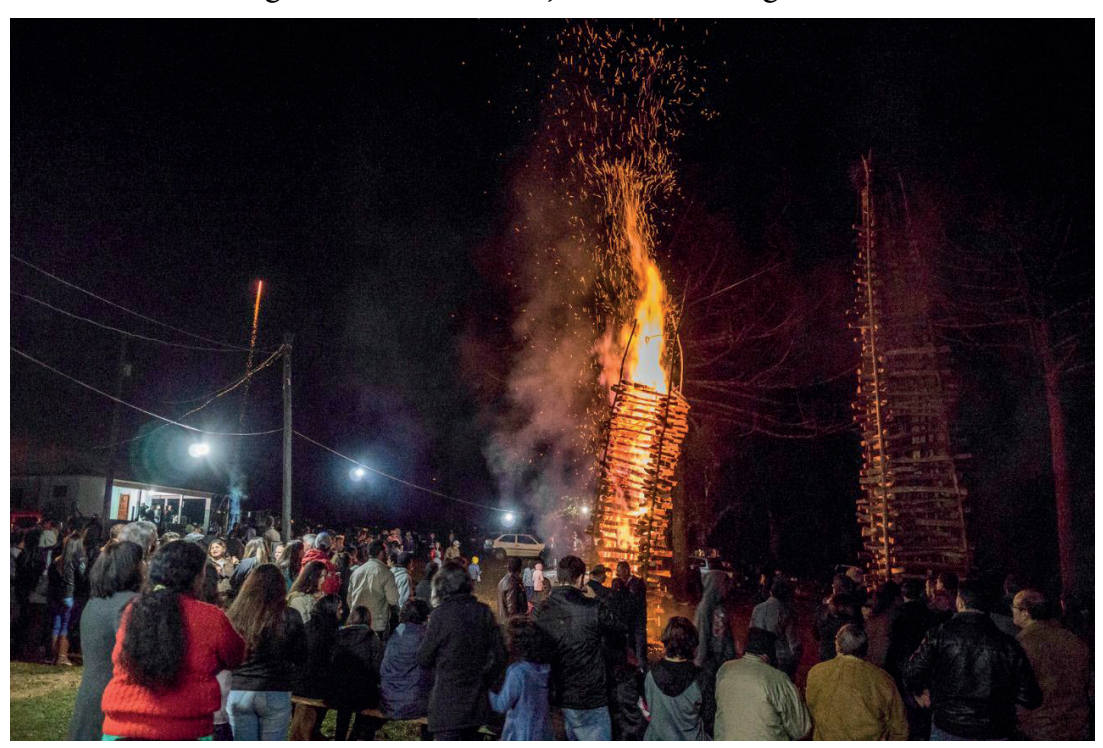

Figura 8 - Entre danças - jogos de leilão

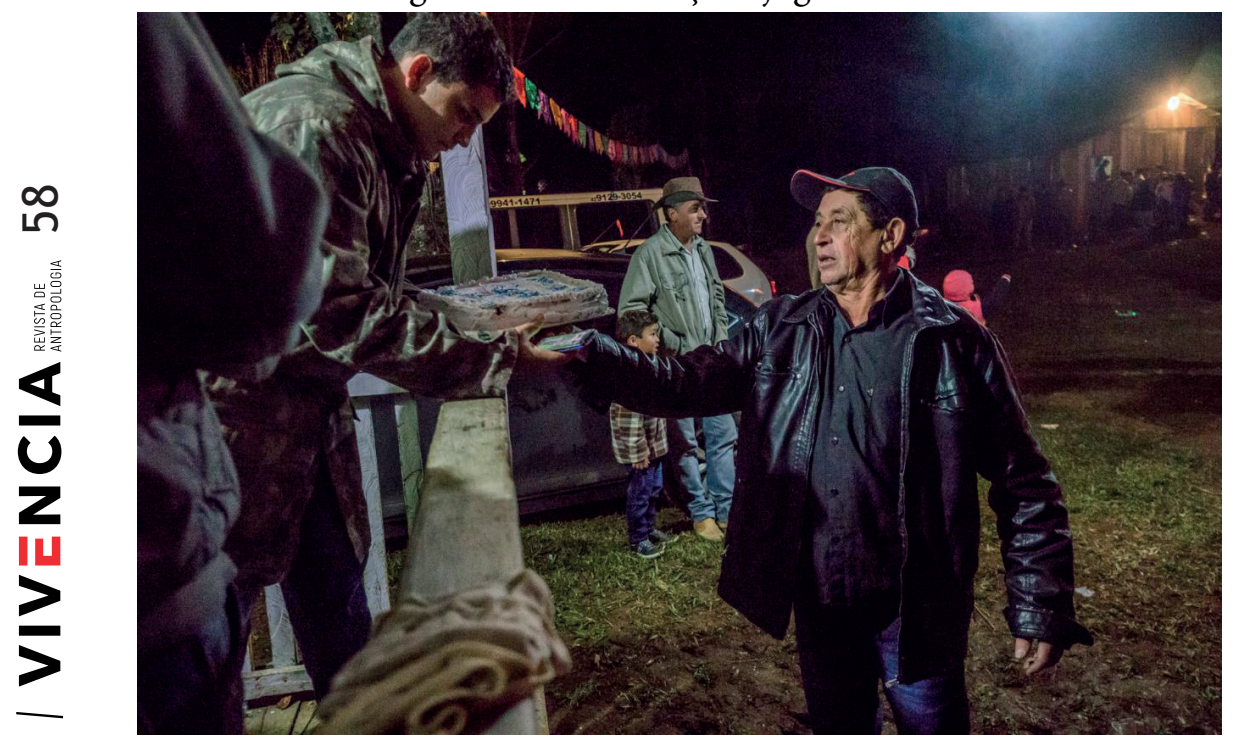


Figura 9 - Procissão de São João Batista - andor

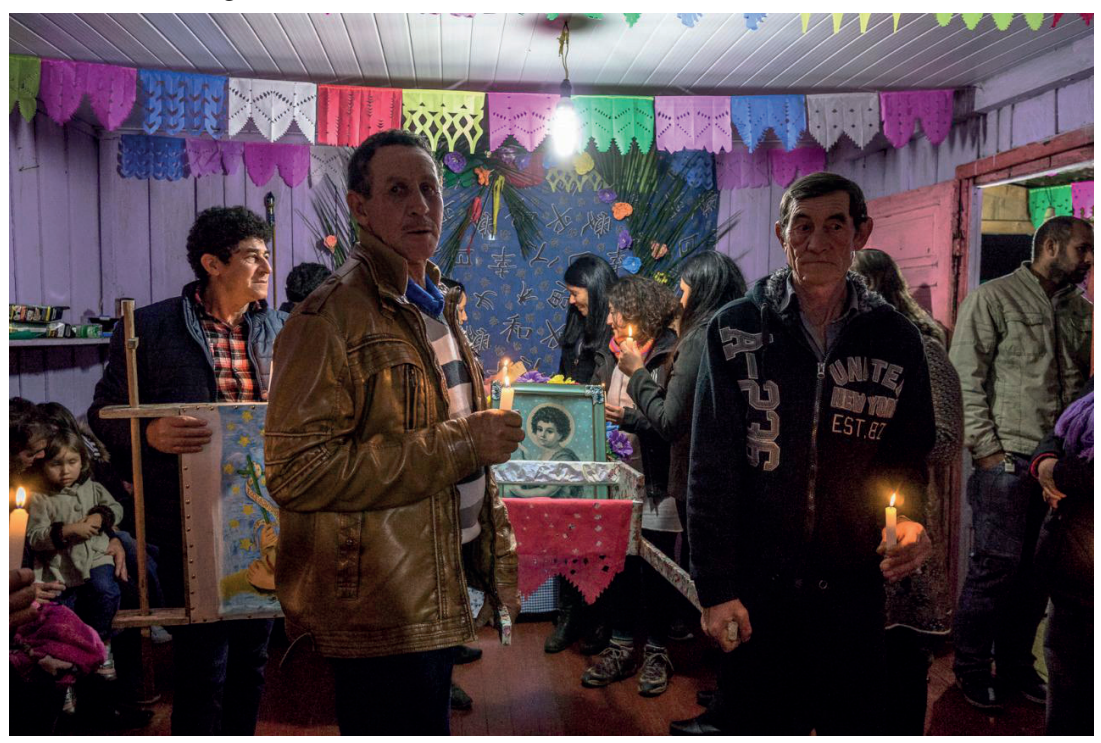

Figura 10 - Procissão de São João Batista

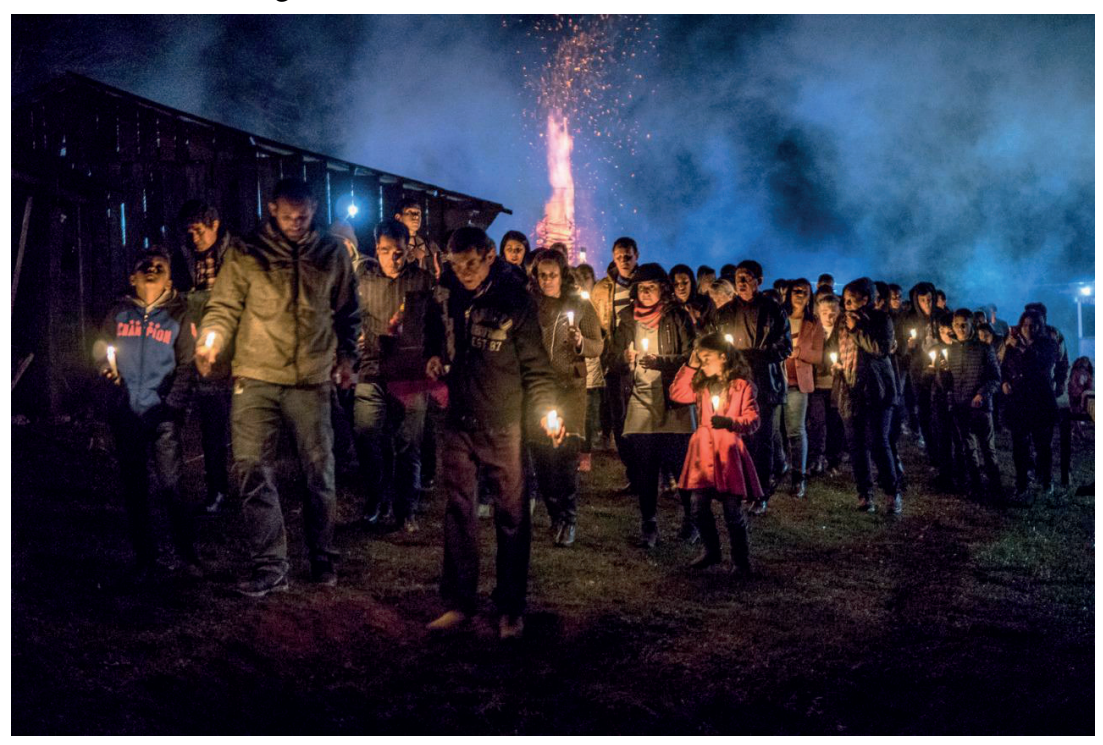

Figura 11 - Procissão de São João Batista - bandeira

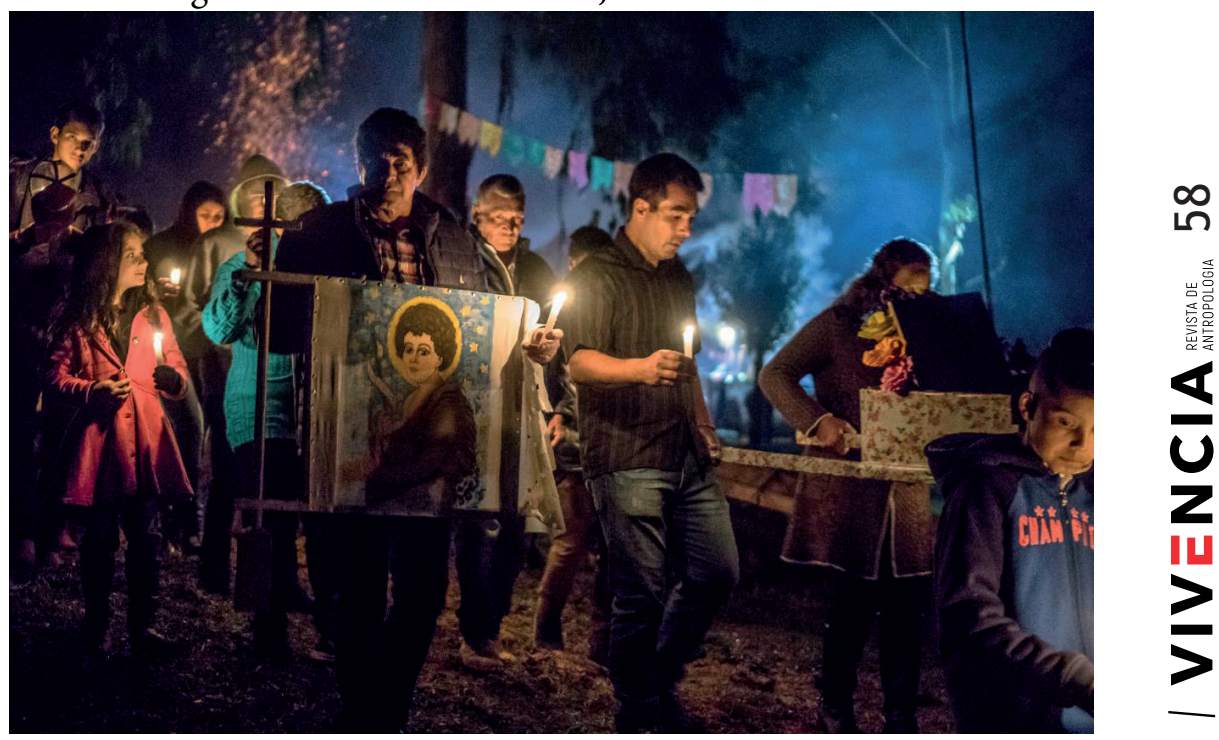


12 - Procissão de São João Batista - lavagem do santo no rio

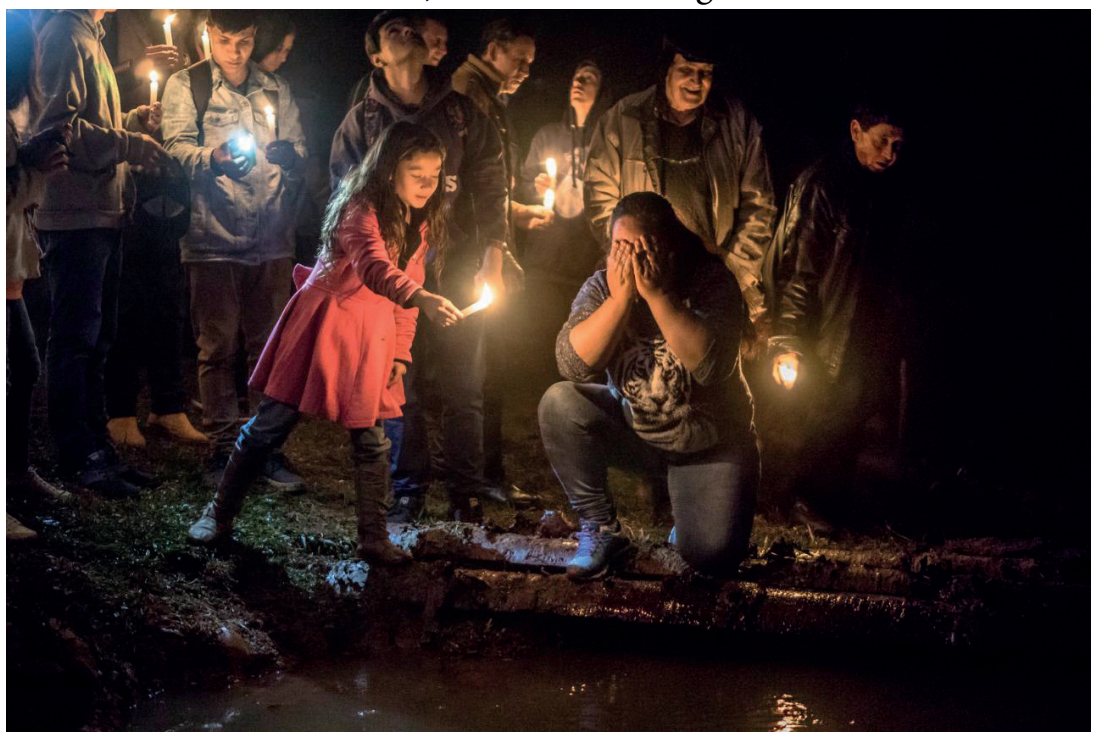

13 - Procissão de São João Batista - erguida do mastro

$\infty$

$\frac{1}{2}$

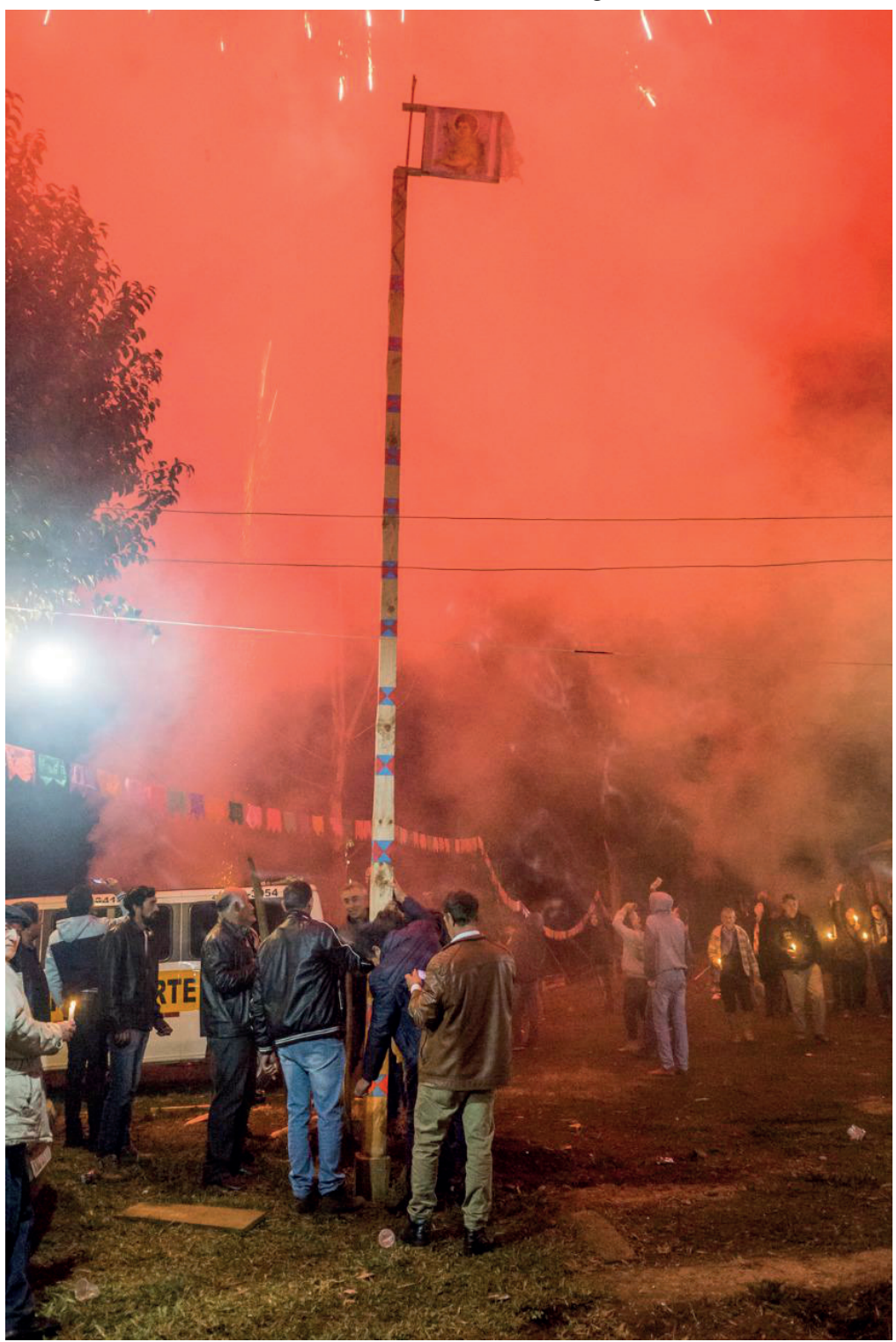




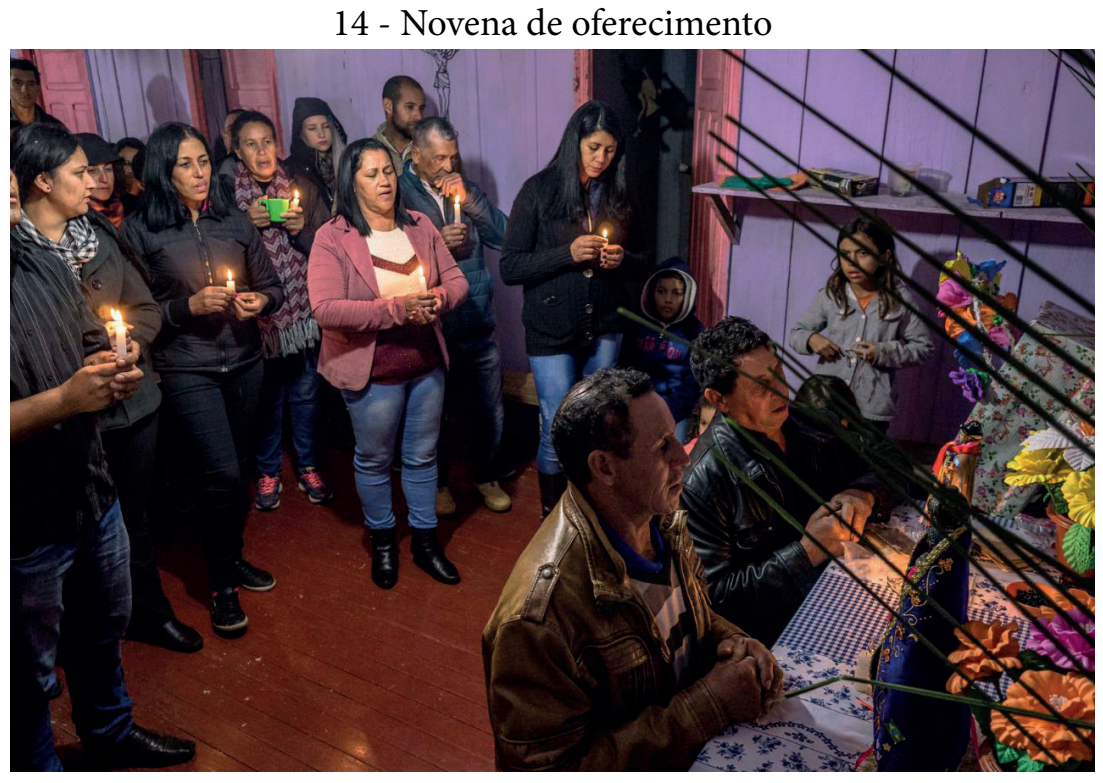

15 - Novena de oferecimento - agradecimento

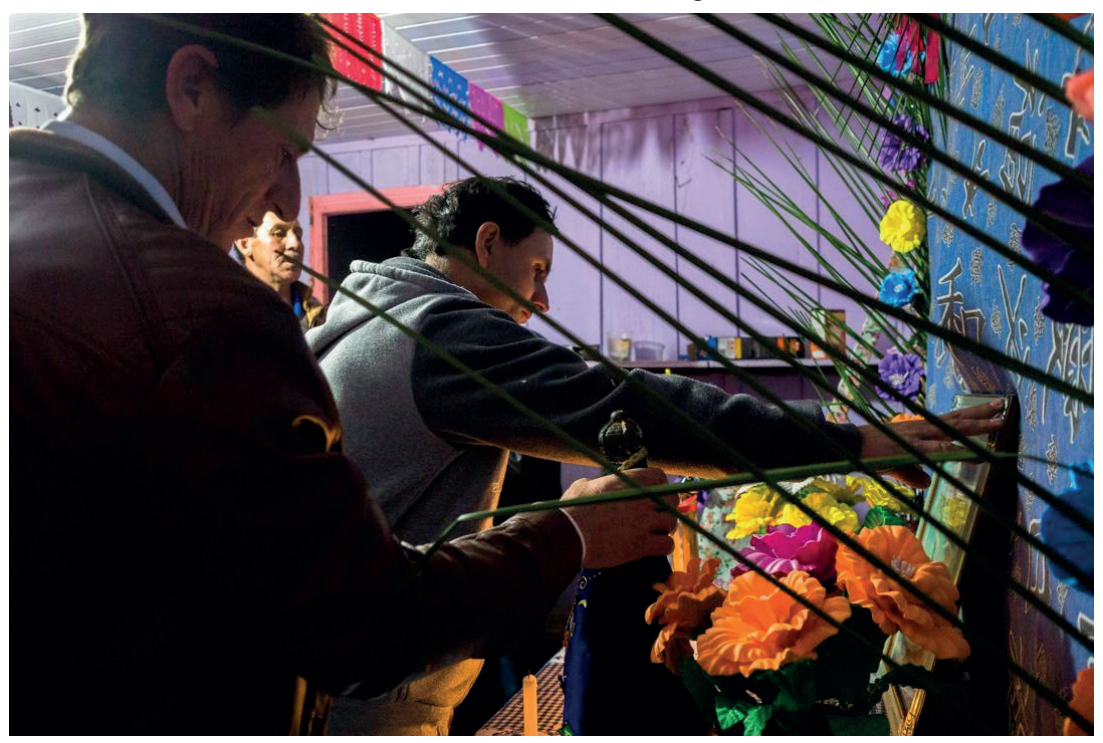

SUBMETIDO EM: 19/12/2020

APROVADO EM: 31/03/2021 